\title{
Patent ductus arteriosus and oxidative stress in preterm infants: a narrative review
}

\author{
Carlo Dani ${ }^{1,2}$, Simone Pratesi ${ }^{2}$ \\ ${ }^{1}$ Department of Neuroscience, Psychology, Drug Research and Child Health, University of Florence, Florence, Italy; ${ }^{2}$ Division of Neonatology, \\ Careggi University Hospital of Florence, Florence, Italy \\ Contributions: (I) Conception and design: All authors; (II) Administrative support: None; (III) Provision of study materials or patients: All authors; \\ (IV) Collection and assembly of data: All authors; (V) Data analysis and interpretation: All authors; (VI) Manuscript writing: All authors; (VII) Final \\ approval of manuscript: All authors. \\ Correspondence to: Carlo Dani, MD. Division of Neonatology, Careggi University Hospital, Largo Brambilla 3, 50134 Firenze, Italy. \\ Email: cdani@unifi.it.
}

\begin{abstract}
The role of oxygen, reactive oxygen species (ROS), and isoprostanes (IsoPs) in regulating patency and closure of patent ductus arteriosus (PDA) have been studied in preterm infants. Also the possible correlation between a hemodynamically significant PDA and its pharmacological treatment with oxidative stress has been investigated. The National Library of Medicine (MEDLINE) database was searched without time limits. Available data demonstrate that free radicals are not always harmful and that ROS and IsoPs play a relevant role in DA closure. On the other hand, a hemodynamically significant PDA can cause oxidative stress and this can partially explain its association with other complications of prematurity related to oxidative stress, such as bronchopulmonary dysplasia (BPD), intraventricular haemorrhage (IVH), and necrotizing enterocolitis (NEC). Some drugs used for pharmacological closure, such as ibuprofen, also have antioxidant effects, and the closure of PDA can restore a proper tissue oxygenation and the balance between pro-oxidant and antioxidant factors. These data support the importance of the relationship between PDA and oxidative stress whose understanding increase our awareness when we approach this prematurity complication in the clinical practice. Further studies might assess the reliability of ROS as possible biomarkers of the risk of developing a hsPDA.
\end{abstract}

Keywords: Patent ductus arteriosus (PDA); oxygen; reactive oxygen species (ROS); free radicals; oxidative stress; preterm infant

Submitted Apr 14, 2020. Accepted for publication Sep 25, 2020.

doi: $10.21037 /$ tp-20-121

View this article at: http://dx.doi.org/10.21037/tp-20-121

\section{Introduction}

Patent ductus arteriosus (PDA) frequently complicates the outcome in preterm infants with respiratory distress syndrome (RDS). Previous studies suggested about $60-70 \%$ of infants born at $<28$ weeks of gestation need pharmacological or surgical treatment for PDA (1). In the last decades, the best management of PDA has been deeply discussed since randomized controlled trials (RCTs) often failed to demonstrate that pharmacological closure of PDA induces relevant benefits in preterm infants (2).
On the other hand, it has been reported that a persistent left-to-right shunt through the ductus can worsen respiratory failure, lower survival rate, and increase risk of intraventricular haemorrhage (IVH) and bronchopulmonary dysplasia (BPD) (1,3-6). Pharmacological closure is commonly performed with indomethacin or ibuprofen. Both are effective in closing PDA in $70-80 \%$ of cases, but can cause severe adverse effects such as gastrointestinal perforations, acute renal failure, and bleeding disorders (7-9). Hence, the recent demonstration that paracetamol is effective in closing PDA was followed by its wide diffusion 
$(10,11)$.

Some relevant physiopathological characteristics of PDA in preterm infant, such as the role of oxygen and reactive oxygen species (ROS) in regulating its patency and closure, were investigated in previous studies, as was the possible association between PDA and its pharmacological treatment with oxidative stress. Nevertheless, these issues are rarely treated in literature. Thus, the objective of this review is to address the relationship between PDA, oxygen, and oxidative stress in preterm infants to clarify these aspects and to contribute to a more complete understanding of this important complication of prematurity. We present the following article in accordance with the NARRATIVE reporting checklist (available at http://dx.doi.org/10.21037/ tp-20-121).

\section{Data sources}

The National Library of Medicine (MEDLINE) database was searched without time limitations. The research was carried out using the following MESH: (I) infant, newborn, preterm, premature; (II) ductus, ductus arteriosus, PDA; (III) oxygen, ROS, free radical; (IV) isoprostane; (V) ibuprofen, indomethacin, paracetamol.

\section{PDA closure and ROS}

Closure of PDA physiologically occurs in the first days of life and is generally distinguished in two phases, functional and structural. However, this distinction is conventional, and the two steps can overlap. Functional closure of ductus arteriosus (DA) is caused by postnatal decrease of circulating prostaglandin $\mathrm{E}_{2}\left(\mathrm{PGE}_{2}\right)$, a potent vasodilator which is synthetized by the placenta during fetal life, and increase of circulating oxygen $\left(\mathrm{PaO}_{2}\right)$ due to the beginning of breathing: these events induce a direct constriction of DA (12).

Ductus arteriosus is very sensitive to oxygen constriction and to explain this strong effect two different mechanisms have been suggested. The first one involves the oxygeninduced activation of cytochrome P450 (CYP450) which mediates the induction of vasoconstrictor endothelin-1 (ET1) $(12,13)$. Several data support this pathway: factors which negatively affect CYP450 function limit the oxygen ductal constrictive effect (14), it has been demonstrated that ET-1 is synthetized in the ductal muscle $(15,16)$, its synthesis is upregulated at birth $(17,18)$ and is positively correlated to the increase of $\mathrm{PaO}_{2}(15,16)$. Moreover, pharmacologic inhibition of ET-1 or its receptors decreases oxygen-induced ductal constriction $(15,19,20)$. The second mechanism of oxygen-induced ductal constriction is represented by the oxygen-induced activation of mitochondrial redox reactions in muscular cells which produce ROS inhibiting specific voltage-gated $\mathrm{K}^{+}$channels $(\mathrm{Kv} 1.5, \mathrm{Kv} 2.1)(21,22)$ and activating L-type $\mathrm{Ca}^{2+}$ channels (23). This mechanism seems to be confirmed by the decrease of oxygen-induced ductal constriction promoted by limiting redox signaling and $\mathrm{K}^{+}$channel activity (24). However, these two pathways might interact and concur in promoting oxygen constriction of DA, compensating for eventual pathophysiological events. In fact, it has been suggested that ET-1 could act also by inhibiting some $\mathrm{K}^{+}$channels (25) or, alternatively, that ET-1-mediated constriction could precede $\mathrm{K}^{+}$channels inhibition (26). On the other hand, all these mechanisms ultimately cause $\mathrm{Ca}^{2+}$-mediated phosphorylation of myosin light chains, induce actin/myosin interaction, and DA smooth muscle cell contraction (27).

A role of isoprostanes (IsoPs) in DA closure has been recently described. IsoPs are synthesized from the free radical-mediated peroxidation of phospholipid-bound arachidonate and, although they are mainly considered as biomarker of oxidative stress, they might promote physiological effects during the fetal and neonatal life, such as DA constriction induced by stimulation of thromboxane receptors (28). van der Sterren et al. studied the vasoactive effects of IsoPs in chicken embryo isolated DA and demonstrated that they can induce a strong DA constriction (28). Chen et al. confirmed these findings demonstrating that oxygen exposure increases IsoPs levels in newborn mouse lung which cause constriction of the isolated term DA by activating the thromboxane A2 (TxA2) receptor (29). Furthermore, they unexpectedly observed that IsoPs induce vasodilation of the preterm isolated DA mediated by the prostaglandin E2 receptor 4 (EP4) (29). These results indicate that IsoPs can promote constrictive or dilatory effects on the DA based on the relative concentration of the TxA2 and EP4 receptors (29). Thus, it seems that the DA maturation is associated with decrease and increase in EP4 and TxA2 receptors, respectively, favoring the prevalence of vasoconstricting effects of stimulation of TxA2 receptors at the end of gestation. Therefore, it can be hypothesised that the transition from the relatively hypoxic fetal environment to the relatively hyperoxic postnatal environment can induce oxidative stress and IsoPs synthesis in newborn infants. This phenomenon could favor DA constriction and 
closure in term infants by activating the TxA2 receptors or DA dilation and PDA development in preterm infants by activating the EP4 receptors. In any case, these mechanisms support the concept of a physiopathological role of oxygen and oxidative stress on the transitional circulation in both healthy term and ill preterm infants.

\section{PDA and oxidative stress}

It has been reported that a hemodynamically significant PDA can increase the risk of BPD, IVH, and necrotizing enterocolitis (NEC). On the other hand, these pathologies are strictly connected with oxidative stress in preterm infants given their large production of ROS and immature antioxidant system (30). Therefore, some authors have wondered if PDA and its pharmacological treatment might affect oxidative stress in these patients.

Forty-three preterm infants born at $<33$ weeks of gestation were studied and their IsoPs urinary levels were measured IsoPs urinary levels before starting treatment of PDA with ibuprofen, after its pharmacological closure, and seven days after the end of treatment (31).

It was found that IsoPs decreased after PDA closure and then increased one week later (31). The initial decrease in IsoP was attributed to the antioxidant properties of ibuprofen capable of scavenging the hydroxyl radical and/ or the chelated iron (32) and to limit neuronal oxidative damage more effectively than naproxen or acetylsalicylic acid (33). Thus, the IsoPs increase observed seven days after the end of treatment has been attributed to the end of ibuprofen antioxidant effect after its suspension (31).

Demir et al. measured in a prospective study the total antioxidant capacity (TAC) and total oxidant status (TOS) in 37 low-birth weight infants who were treated with ibuprofen for a hemodynamically significant PDA in comparison with 40 low-birth weight infants without PDA (34). Before the treatment, TOS and TAC were lower in infants with PDA than in infants without it, but the difference disappeared after the pharmacological closure (34). The authors speculated that, similarly to other congenital heart diseases with left-to-right shunt, a hemodynamically significant PDA can induce a high oxygen requirement, increase the synthesis of ROS, and lead to an imbalance between oxidants and antioxidant agents and the development of oxidative stress (34). Thus, the PDA closure could exert an antioxidant effect and restore a proper balance. Interestingly, they found that S-100B protein level, an accurate marker of cerebral injury, was not affected by
PDA suggesting that the brain can compensate for oxidative stress and impaired tissue perfusion (34).

Inayat et al. prospectively studied 53 preterm infants with gestational age $\leq 32$ weeks of whom 30 developed a hemodynamically significant PDA requiring pharmacological $(n=30)$ and surgical treatment $(n=11)$, and 23 did not (35). They found that plasma superoxide dismutase (SOD) activity was lower in infants with PDA than in infants without PDA, and that it decreased significantly after PDA closure (35). Moreover, they observed that IsoPs plasma levels were lower in infants with PDA than in infants without PDA, and that it increased significantly after PDA closure (35). They speculated that a low antioxidant status, particularly a low SOD activity, can favor the development of PDA by reducing the synthesis of $\mathrm{H}_{2} \mathrm{O}_{2}$, a molecule that might be a critical link in redox signaling and DA constriction (36). On the other hand, the post-closure decrease of SOD activity might be due to the antioxidant effect of pharmacological treatment (36). The association between low levels of IsoPs and the development of PDA confirms previous findings on the role of IsoPs in the mechanism of closure of DA by promoting its constriction $(28,29)$. Otherwise, the reported posttreatment increase of IsoPs might likely be due to increased tissue oxygenation, ROS production, and oxidative stress.

These data as a whole highlight a correlation between PDA, its pharmacological closure, and oxidative stress in preterm infants. In fact, they suggest that a low level of ROS might contribute to the development of a hemodynamically significant PDA (35); that a hemodynamically significant PDA can induce oxidative stress by increasing tissue oxygen requirement (34); and that the PDA closure could restore a proper oxidative balance due to the normalization of tissue oxygenation and pharmacologic antioxidant effect of ibuprofen (31).

Future research might be aimed at identifying reliable biomarkers correlating with the risk of developing a hsPDA using molecules associated with the oxidative stress, such as IsoPs which can be painlessly measured in urines. Such biomarkers could be suitable in daily practice for the management of hsPDA combined with echocardiography which is the best current tool for studying PDA in preterm infants, assessing its progression and deciding its treatment.

\section{Conclusions}

PDA is a frequent complication of very preterm infants whose etiology is multifactorial. The effect on DA closure 
of postnatal increase of $\mathrm{PaO}_{2}$ and decrease of $\mathrm{PGE}_{2}$ is well known, but, as previously mentioned, also ROS and IsoPs play a relevant role. This confirms that ROS can have a dual effect as both toxic and beneficial compounds, and that free radicals do not always have a negative effect; in fact, it has been shown that at low or moderate concentrations, they play a physiological role in cellular and tissue maturation during the fetal and neonatal period (30). On the other hand, a hemodynamically significant PDA can cause oxidative stress and this could partially explain its association with other complications of prematurity related to oxidative stress, such as BPD, IVH, and NEC. On the contrary, the closure of PDA can restore a proper tissue oxygenation and the balance between pro-oxidant and antioxidant factors. Moreover, some drugs used for pharmacological closure, such as ibuprofen, also have antioxidant effects. These data support the importance of the relationship between PDA and oxidative stress whose knowledge can increase our awareness when we approach this prematurity complication in the clinical practice.

Further studies might assess the reliability of ROS as possible biomarkers of the risk of developing a hsPDA.

\section{Acknowledgments}

Funding: None.

\section{Footnote}

Reporting Checklist: The authors have completed the NARRATIVE reporting checklist. Available at http:// dx. doi. org/10.21037/tp-20-121

Conflicts of Interest: Both authors have completed the ICMJE uniform disclosure form (available at http://dx. doi. org/10.21037/tp-20-121). The authors have no conflicts of interest to declare.

Ethical Statement: The authors are accountable for all aspects of the work in ensuring that questions related to the accuracy or integrity of any part of the work are appropriately investigated and resolved.

Open Access Statement: This is an Open Access article distributed in accordance with the Creative Commons Attribution-NonCommercial-NoDerivs 4.0 International License (CC BY-NC-ND 4.0), which permits the noncommercial replication and distribution of the article with the strict proviso that no changes or edits are made and the original work is properly cited (including links to both the formal publication through the relevant DOI and the license). See: https://creativecommons.org/licenses/by-nc-nd/4.0/.

\section{References}

1. Hamrick SE, Hansmann G. Patent ductus arteriosus of the preterm infant. Pediatrics 2010;125:1020-30.

2. El-Khuffash A, Weisz DE, McNamara PJ. Reflections of the changes in patent ductus arteriosus management during the last 10 years. Arch Dis Child Fetal Neonatal Ed 2016;101:F474-8.

3. Brooks JM, Travadi JN, Patole SK, et al. Is surgical ligation of patent ductus arteriosus necessary? The Western Australian experience of conservative management. Arch Dis Child Fetal Neonatal Ed 2005;90:F235-9.

4. Kaempf JW, Wu XY, Kaempf AJ, et al. What happens when the patent ductus arteriosus is treated less aggressively in very low birth weight infants? J Perinatol 2012;32:344-8.

5. Liebowitz M, Clyman RI. prophylactic indomethacin compared with delayed conservative management of the patent ductus arteriosus in extremely preterm infants, effects on neonatal outcomes. J Pediatr 2017;187:119-126.e1.

6. Schena F, Francescato G, Cappelleri A, et al. Association between hemodynamically significant patent ductus arteriosus and bronchopulmonary dysplasia. J Pediatr 2015;166:1488-92.

7. Malviya MN, Ohlsson A, Shah SS. Surgical versus medical treatment with cyclooxygenase inhibitors for symptomatic patent ductus arteriosus in preterm infants. Cochrane Database Syst Rev 2013;3:CD003951.

8. Fowlie PW, Davis PG. Prophylactic intravenous indomethacin for preventing mortality and morbidity in preterm infants. Cochrane Database Syst Rev 2002;3:CD000174.

9. Ohlsson A, Walia R, Shah SS. Ibuprofen for the treatment of patent ductus arteriosus in preterm or low birth weight (or both) infants. Cochrane Database Syst Rev 2018;9:CD003481.

10. Ohlsson A, Shah PS. Paracetamol (acetaminophen) for patent ductus arteriosus in preterm or low birth weight infants. Cochrane Database Syst Rev 2018;4:CD010061.

11. Dani C, Mosca F, Cresi F, et al. Patent ductus arteriosus in preterm infants born at 23-24 weeks' gestation: Should we pay more attention? Early Hum Dev 2019;135:16-22. 
12. Coceani F, Baragatti B. Mechanisms for Ductus Arteriosus Closure. Semin Perinatol 2012;36:92-7.

13. Crockett SL, Berger CD, Shelton EL, et al. Molecular and Mechanical Factors Contributing to Ductus Arteriosus Patency and Closure. Congenit Heart Dis 2019;14:15-20.

14. Coceani F, Breen CA, Lees JG. Further evidence implicating a cytochrome P-450-mediated reaction in the contractile tension of the lamb ductus arteriosus. Circ Res 1988;62:471-7.

15. Coceani F, Kelsey L, Seidlitz E. Evidence for an effector role of endothelin in closure of the ductus arteriosus at birth. Can J Physiol Pharmacol 1992;70:1061-4.

16. Coceani F, Kelsey L. Endothelin-1 release from the lamb ductus arteriosus: Are carbon monoxide and nitric oxide regulatory agents? Life Sci 2000;66:2613-23.

17. Costa M, Barogi S, Socci ND. Gene expression in ductus arteriosus and aorta, Comparison of birth and oxygen effects. Physiol Genomics 2006;25:250-62.

18. Yokoyama U, Sato Y, Akaike T. Maternal vitamin A alters gene profiles and structural maturation of the rat ductus arteriosus. Physiol Genomics 2007;31:139-57.

19. Taniguchi T, Azuma H, Okada Y. Endothelin-1-endothelin receptor type A mediates closure of rat ductus arteriosus at birth. J Physiol 2001;537:579-85.

20. Shen J, Nakanishi T, Gu H. The role of endothelin in oxygen induced contraction of the ductus arteriosus in rabbit and rat fetuses. Heart Vessels 2002;16:181-8.

21. Thébaud B, Michelakis ED, Wu XC. Oxygen-sensitive $\mathrm{Kv}$ channel gene transfer confers oxygen responsiveness to preterm rabbit and remodeled human ductus arteriosus, Implications for infants with patent ductus arteriosus. Circulation 2004;110:1372-9.

22. Kajimoto H, Hashimoto K, Bonnet SN. Oxygen activates the Rho/Rho-kinase pathway and induces RhoB and ROCK-1 expression in human and rabbit ductus arteriosus by increasing mitochondria-derived reactive oxygen species: A newly recognized mechanism for sustaining ductal constriction. Circulation 2007;115:1777-88.

23. Thébaud B, Wu XC, Kajimoto H. Developmental absence of the $\mathrm{O} 2$ sensitivity of L-type calcium channels in preterm ductus arteriosus smooth muscle cells impairs $\mathrm{O} 2$ constriction contributing to patent ductus arteriosus. Pediatr Res 2008;63:176-81.

24. Weir EK, Archer SL. The role of redox changes in oxygen sensing. Respir Physiol Neurobiol 2010;174:182-91.

25. Shimoda LA, Sylvester JT, Sham JSK. Inhibition of voltage-gated $\mathrm{K}_{\text {_ }}$ current in rat intrapulmonary arterial myocytes by endothelin-1. Am J Physiol 1998;274:L842-L853.

26. Keck M, Resnik E, Linden B. Oxygen increases ductus arteriosus smooth muscle cytosolic calcium via release of calcium from inositol triphosphate-sensitive stores. Am J Physiol Lung Cell Mol Physiol 2005;288:L917-L923.

27. Stoller JZ, Demauro SB, Dagle JM, et al. Current perspectives on pathobiology of the ductus arteriosus. J Clin Exp Cardiolog 2012;8:S8-001.

28. van der Sterren S, Villamor E. Contractile effects of 15-E2t-isoprostane and 15-F2t-isoprostane on chicken embryo ductus arteriosus. Comp Biochem Physiol A Mol Integr Physiol 2011;159:436-44.

29. Chen JX, O'Mara PW, Poole SD, et al. Isoprostanes as physiological mediators of transition to newborn life, novel mechanisms regulating patency of the term and preterm ductus arteriosus. Pediatr Res 2012;72:122-8.

30. Ozsurekci Y, Aykac K. Oxidative Stress Related Diseases in Newborns. Oxid Med Cell Longev 2016;2016:2768365.

31. Longini M, Perrone S, Vezzosi P. Isoprostane levels in urine of preterm newborns treated with ibuprofen for patent ductus arteriosus closure. Pediatr Nephrol 2011;26:105-9.

32. Hamburger SA, McCay PB. Spin trapping of ibuprofen radicals, evidence that ibuprofen is a hydroxyl radical scavenger. Free Radic Res Commun 1990;9:337-42.

33. Milatovic D, Zaja-Milatovic S, Montine KS, et al. Neuronal oxidative damage and dendritic degeneration following activation of CD14-dependent innate immune response in vivo. J Neuroinflammation 2004;1:20.

34. Demir N, Ece I, Peker E. Impact of patent ductus arteriosus and subsequent therapy with ibuprofen on the release of S-100B and oxidative stress index in preterm infants. Med Sci Monit 2014;20:2799-805.

35. Inayat M, Bany-Mohammed F, Valencia A. Antioxidants and biomarkers of oxidative stress in preterm infants with symptomatic patent ductus arteriosus. Am J Perinatol 2015;32:895-904.

36. Weir EK, Obreztchikova M, Vargese A, et al. Mechanisms of oxygen sensing, a key to therapy of pulmonary hypertension and patent ductus arteriosus. Br J Pharmacol 2008;155:300-7.

Cite this article as: Dani C, Pratesi S. Patent ductus arteriosus and oxidative stress in preterm infants: a narrative review. Transl Pediatr 2020;9(6):835-839. doi: 10.21037/tp-20-121 